\title{
Adoption of institutional repositories for electronic theses and dissertations projects in Zimbabwe's public academic libraries
}

\author{
Mass Masona Tapfuma ${ }^{1}$ and Ruth Geraldine Hoskins ${ }^{2}$ \\ tapfumam@ukzn.ac.za ORCID: 0000-0002-7830-1503 \\ hoskinsr@ukzn.ac.za ORCID: 0000-0002-9099-5544
}

\begin{abstract}
Received: 14 February 2020
Accepted: 1 July 2021

Theses and dissertations (TDs) are an invaluable scholarly literature output of university graduates, contributing to the fulfilment of university mandates to impact national development through research. Public universities in Zimbabwe have adopted open access institutional repositories (IRs) in which to store electronic theses and dissertations (ETD). This study sought to determine the development levels of ETD collections, establish the software platforms being used, and discover challenges being faced in developing ETD collections in repositories at these universities. The Unified Theory of Acceptance and Use of Technology model was adopted, and a mixed methods approach was employed. Data were collected through questionnaires, interviews and bibliometric analyses from library directors, assistant/IR librarians, IRs, policy documents and Directory of Open Access Repositories (OpenDOAR) at eight universities. Qualitative data were analysed thematically while the Statistical Package for the Social Sciences (SPSS) was adopted to analyse quantitative data. Findings showed slow development of ETD collections, with DSpace as the software of choice across the universities. Faculty cooperation in depositing ETDs is minimal, thus affecting progress of ETD initiatives. Mandating the deposit of electronic copies of TDs would populate repositories and increase visibility of research.
\end{abstract}

Keywords: Electronic theses and dissertations, institutional repositories, digital repositories, student research, Zimbabwe

\section{Introduction and background}

Universities play a significant role in research and development, but their value can only be felt when the research generated by their institutions' academics, researchers and postgraduate students is easily findable and accessible for the public good. A gap was observed in the accessibility and availability of knowledge from universities in the southern African region (Abrahams et al. 2008). Using the Web of Science, Robert Tijssen and Jos Winnink - from Leiden University in the Netherlands - plotted Africa's research output between 2007 and 2017 by counting papers with at least one Africa-domiciled author and found that in 2007 the output was 1.9\% which increased to 3.1\% in 2017 (Nordling 2018). South African research has a reasonable degree of visibility (Abrahams, Burke \& Mouton 2010: 24) as the country has attracted many students from across the region (Trotter et al. 2014: 37), hence its success and supremacy in research productivity. Out of the 1,546 doctorates produced in the region in 2010 , South Africa accounted for $89 \%$ while the remaining $11 \%$ was produced by the other countries (Kotecha, Walwyn \& Pinto 2011: 12). The World Bank/Elsevier report (2014) puts sub-Saharan Africa's share of global research output at less than $1 \%$, which places Africa's research performance at a much lower level than expected if the potential contribution of researchers on the continent is to be realised for the public good (Adams, King \& Hooks 2010).

It was with this information as background and the realisation that TDs were inaccessible, that the Association of African Universities (AAU 2019) initiated and supports "efforts towards putting Africa's research output onto the mainstream of world knowledge" resulting in the birth of the Database of African Theses and Dissertations - Research (DATAD-R) in 2000. This initiative came on the heels of a pilot project to index, abstract and distribute theses and dissertations from African universities (AAU 2019). TDs are the most underutilised resource in Africa as they are left to gather dust on library shelves, or they are held in inaccessible places preventing publications from being extracted from them. When printed TDs are deposited in the library, access to them is restricted to use on campus or within the library. The DATAD OnLine project successfully launched its online database of abstracts in April 2003, but only four countries participated, namely: Kenya, Ghana, Zimbabwe and South Africa. Evidently there has been very little progress in making Africa's research output increasingly visible and accessible in the public domain. Despite this gloomy picture of AAU efforts, hope is not lost as

1. Mass Masona Tapfuma is Postdoctoral Fellow in the Information Studies Department, School of Social Sciences, University of KwaZulu-Natal, South Africa

2. Ruth Geraldine Hoskins is Professor and Dean of Teaching and Learning, College of Humanities, University of KwaZulu-Natal, South Africa 
universities moved to establish institutional repositories (IRs) to capture, store, archive and widely disseminate research produced by their students and scholars. TDs constitute the biggest portion of IR content. A study by Xia and Opperman (2010) found that almost $50 \%$ of contributions to IRs were from students in the form of theses and student journals (project papers). Accessibility and visibility of electronic theses and dissertations (ETDs) on the internet is central to (re)generation of new knowledge and sustainable development, and assists in averting duplication of research. Using the Unified Theory of Acceptance and Use of Technology (UTAUT), this study explored the utilisation of IRs in Zimbabwe's public universities to increase visibility of students' scholarship.

\section{Statement of the problem}

Studies (Abrahams et al. 2008, Mouton et al. 2008) revealed that research productivity in southern African universities, in comparison to other regions across the globe, was low and that avenues of dissemination of the available grey literature were limited. TDs form the base of the pyramid of knowledge production from which publications are drawn (Abrahams et al. 2008). Therefore, recommendations were made for the universities to adopt Open Access (OA) platforms to increase availability, accessibility and visibility of their research output. IRs were set up in Zimbabwe's public universities for this purpose, but studies have shown that most universities struggle to make their IRs active and vibrant with most being $85 \%$ empty (Bankier \& Perciali 2008, Harnad 2011). To ascertain the achievement of the OA agenda to increase availability and visibility of local scholarship for the public good, this study explored the level of development of the ETD collections in repositories and established challenges being experienced by libraries in ETD collection development.

\section{Objectives of the study}

The specific objectives were to:

- determine the level of development of TD collections in institutional repositories of public universities in Zimbabwe;

- establish the preferred software platforms for ETDs; and

- discover the challenges faced by the university libraries in developing the repositories.

\section{Unified Theory of Acceptance and Use of Technology}

The UTAUT model developed by Venkatesh et al. (2003) is an amalgam of eight technology acceptance theories concerned with individuals' decision-making behaviour regarding acceptance and adoption of technology (Oye, lahad and Rahim 2012). Through the model, implementers of a new technology are able to understand factors contributing to its acceptance and use so that they can timeously plan interventions for increased adoption and usage of the system by stakeholders. The UTAUT model has four key determinants of usage intention and behaviour: performance expectancy, effort expectancy, social influence and facilitating conditions. These determinants of technology usage behaviour are mediated by variables of age, gender, experience and voluntariness of use. These mediating variables were not considered in this study.

The strongest predictor of behaviour intention in both voluntary and mandatory settings is the 'performance expectancy' variable; it is concerned with the user's level of belief that by using the system they will attain gains in job performance. The variable 'effort expectancy' refers to the level of ease of use of the system. The model assumes that, despite the variable being significant in both mandatory and voluntary situations, it is only significant in the early stages (post training) and it slows down over time. 'Social influence' refers to the extent to which a person perceives that peers (for example, consortium members, co-workers or the academic community) expect them to use the new system. 'Facilitating conditions' refers to the extent to which a person believes that an organisational and technical infrastructure exists to support use of the system. The model assumes that 'facilitating conditions' will not significantly influence 'behavioural intention' (Venkatesh et al. 2003). The UTAUT model is applicable for both voluntary and mandatory usage participants. This study assumed that some universities have policies that make usage of ETDs and IRs mandatory, while others do not.

\section{Literature review}

Technological developments in the twenty-first century have seen a significant change occurring in the storage, preservation and dissemination of TDs from the traditional bound format to the electronic format known as ETDs. This change has improved findability and distribution of student-generated research findings and enabled knowledge sharing beyond geographical boundaries. Submission of bound TDs to the library limited access to them, as it obliged prospective users to visit the library to retrieve printed copies which, in some cases, could only be consulted in the library. With the establishment of IRs, many universities incorporated ETD programmes into their IR platforms. This strategy is supported by Lynch (2017: 128) who proffered that an IR "can be instrumental in advancing the electronic theses and dissertations movement."

TDs are a cherished academic literature genre (Yiotis 2008), produced by postgraduate students at Master's and PhD levels. Postgraduate programmes offered in most disciplines across the globe require their students to carry out research 
as a condition for them to complete a programme. Perrin, Winkler and Yang (2015), in concurrence with McCutcheon (2011), said that ETDs have become the best way of distributing student scholarship as they increase findability and dissemination. A study in 2000 at Virginia Tech University established that circulation of a print thesis in a year occurred twice while that of a dissertation happened three times per year in the first four years of availability in the library (McCutcheon 2011). Contrary to this, a single ETD had 650 downloads, on average, with an observed interest coming from external international audiences. Because of their nature, TDs have been classified as grey literature which is described as:

... manifold document types produced on all levels of government, academics, business and industry in print and electronic formats that are protected by intellectual property rights, of sufficient quality to be collected and preserved by library holdings or institutional repositories, but not controlled by commercial publishers i.e., where publishing is not the primary activity of the producing body. (Schöpfel 2010).

Submission of TDs to a university school or faculty is mandatory, though deposit to the library in some institutions remains voluntary. Universities with ETD programmes require students to submit an electronic version of the thesis or dissertation to facilitate its upload. This means that for ETD programmes to succeed, "a variety of collaborative, managerial and preservation skillsets" (Perrin, Winkler \& Yang 2015: 99) is required as ETDs transform the traditional practice of publishing TDs (Boock \& Kunda 2009, Early and Taber 2010, Perrin, Winkler \& Yang 2015, Yiotis 2008); the library has to increasingly work together with the graduate or research office, faculties and scholars. The graduate office is responsible for policy formulation regarding collection and deposit of ETDs to the library; it works closely with faculties and supervisors of TDs in ensuring that submission procedures are observed. The library's product offering and collection development practice is also transformed by inclusion of ETDs, some of which have an embargo period of six months to a year before they can be published in full. Library staff would therefore need training in copyright clearance. They would also need to consult with students and supervisors to track the embargo periods to know when theses or dissertations are ready for publication.

The United Nations Educational, Scientific and Cultural Organisation (UNESCO 2001: 2.1 section) proffers that TDs reflect the quality of intellectual output of a university's graduates and its ability to guide and support original research by students. Schöpfel and Rasuli (2018: 212) determined that several factors contribute to the quality of a PhD thesis, including: the quality of supervision, the university's reputation and excellence, and the student's research and writing skills. The bottom line is that TDs are an essential information resource in the scholarly communication ecosystem, as they contribute to academic discourse and the continuous cycle of information (re)generation for the development of local solutions to local problems and they contribute to the achievement of sustainable development goals.

ETD repositories have several advantages for institutions, students and scholars. They improve graduate education, and they preserve and promote knowledge sharing (Suleman \& Fox 2003, Yiotis 2008). Students stand to benefit more from ETDs as they are exposed to emerging formats and types of TDs resulting in re-conceptualisation of academic writing (Fox 2001, Moxley 2001, Yiotis 2008). Visibility and exposure of students' work is also increased as ETDs showcase a university's intellectual output to a global audience. Moxley (2001) discerned that ETDs attract potential funding opportunities for students and their faculties due to increased visibility of their works which increases their recognition in their profession. In addition, storage space is managed by the library and provides immediate delivery of research to both local and distant users. Access barriers are removed, enabling borderless access and discovery at low or no cost to the remote user. The fact that a remote user no longer spends money and time travelling to the library makes ETDs one of the most favoured avenues of TD delivery and distribution by the scholarly community (Fox, MacMillan \& Srinivasan 2012, Perrin, Winkler \& Yang 2015). However, Schöpfel and Rasuli (2018) said that creation of ETD repositories does not guarantee accessibility and availability of TDs. Depending on the supervisor, student, faculty or discipline, many ETDs remain embargoed, or, in some cases, access is restricted to on-campus users (Prost \& Schöpfel 2014, Schöpfel \& Rasuli 2018).

Institutional repositories conform to an internationally accepted set of technical metadata standards, that is, Open Archives Initiative Protocol for Metadata Harvesting (OAI-PMH) in which the bibliographic details (author's name, institutional affiliation, title of article, abstract, keywords and so forth) of a record are captured. Standards facilitate indexing of the repository's contents by web search engines like Google, thereby enabling freely available global research through online OA databases (Swan 2009). It is important to note that institutional repositories have a long-term preservation objective (Lynch 2003) seeking to address future storage of information (Early \& Taber 2010, Perrin, Winker \& Yang 2015). Some libraries have instituted policies mandating deposit of both printed copies and electronic copies of TDs; others, for instance, Vanderbilt University during its pilot project, required electronic submissions from participating departments; the University of Kentucky offers an option to submit either print or electronic versions; while others have simply done away with print copies and only accept electronic copies (Yiotis 2008). Yiotis (2008) reported that even students who participated 
in the pilot of the ETD management system at the Sheridan Libraries of the Johns Hopkins University in 2006 were not exempt from submitting printed versions of their theses or dissertations to the library.

The choice of electronic publishing systems where ETDs can be hosted is of interest to institutions wishing to establish ETD repositories. Studies show that DSpace is the preferred software for repositories because of its flexibility for customisation, followed by bepress' Digital Commons, Eprints and Greenstone (Rieh et al. 2007, Witten et al. 2005, Xia \& Opperman 2010). The DSpace platform was developed for "long-term digital content storage and preservation [and]... as a service of the libraries" (Chudnov 2001: 284). The software is ideal for use in large institutions (Ravikumar \& Ramanan 2014). A study by Ezema and Ugwu (2013) on the status, challenges and strategies of ETDs in Nigerian universities found a few universities with a sizeable number of TDs though $62.5 \%$ of the universities did not have ETD projects. Some of the challenges experienced by the universities included irregular power supply, absence of funding, poor ICT infrastructure, and the lack of ETD policy. The authors recommended that the government should provide adequate funding to facilitate implementation of ETD projects and development of ETD policies at the universities.

\section{Methodology}

The study adopted a case study design and employed a mixed methods approach to obtain a holistic picture of IR development in Zimbabwe's public universities. Interviews were conducted with eight directors of research and eight library directors while semi-structured questionnaires were distributed to forty assistant/faculty librarians. Twenty-five assistant/faculty librarians completed the questionnaires, giving a $62.5 \%$ response rate. Directors of research were included since they are policy makers in the institutions while librarians are responsible for the development of IRs. Five universities' $\mathrm{OA} / \mathrm{IR}$ policies were made available for analysis; two universities were still in the process of drafting their policies. Websites of the universities, as well as the Directory of Open Access Repositories (OpenDOAR), Registry of Open Access Repositories (ROAR) and the Database of African Theses and Dissertations-Research (DATAD-R), were analysed. The units of analysis comprised eight public universities, namely: Bindura University of Science Education, Chinhoyi University of Technology, Great Zimbabwe University, Harare Institute of Technology, Lupane State University, Midlands State University (MSU), National University of Science and Technology (NUST) and the Zimbabwe Open University. The University of Zimbabwe (UZ) declined to participate, while three universities, Gwanda State University, Manicaland State University of Applied Sciences and Marondera University of Agricultural Science and Technology, were excluded because they were under the tutelage of NUST, MSU and UZ respectively. For confidentiality, the identity of the institutions was not revealed in data analysis. Due to the relatively small size of the population, a census was done as it helped to eliminate sampling error and a desirable level of precision would be achieved.

\section{Findings}

This section presents and discusses the results of the study in line with the study's objectives.

\subsection{Development of ETD programmes in the repositories}

Results in Table 1 show that all eight universities had IRs which have been operational for nine to thirteen years. Seven universities run two repositories, that is, six universities keep one for use by the internal university community and the other one is in the public domain. One of these, University 7, has both repositories in the public domain but only one hosts ETDs. One institution maintains one OA repository in which ETDs are excluded for intellectual property reasons. This university collects printed versions of TDs. The intranet repositories in the universities house examination papers and largely undergraduate dissertations. Six universities include first class undergraduate dissertations and postgraduate ETDs on IRs that are in the public domain, while one university's repository includes PhD theses only. The reason for keeping an intranet repository was, according to one library director, so as not to jeopardise the institutions' image by showcasing substandard work. All the universities' repositories are multidisciplinary, and content is organised by discipline into communities which have further subdivisions for specific subjects. The faculties, schools, institutes or centres within a university constitute the communities, then departments or sections form the sub-groups, called sub-units on the DSpace platform. Two universities' repositories have ETD programmes listed as communities while the other five group their ETDs together with other items within subject or departmental communities.

The results in Table 1 show that University 1 has the highest number $(1,667)$ of ETDs at both the undergraduate and Master's levels, followed by University 5 with 304 ETDs. University 3 has 134 and the other two have sixty-two and twentyfive ETDs respectively. It should be noted that the number of records in the IRs of two universities (6 and 7) could not be determined. A search in University 5's repository revealed duplicated records with one item having two to three entries. Therefore, the number of items in the repository is not a true reflection of the size of the ETD collection. Table 1 shows that only two repositories provide full-text ETDs, while only abstracts and metadata are made available on the rest. The study also sought to establish if the repositories were registered with OpenDOAR, ROAR or any other open-source platform. 
Interviews revealed that five universities had registered their repositories with OpenDOAR and, of these five, two were also registered with ROAR. However, analysis of OpenDOAR, ROAR and DATAD-R revealed that all the repositories which were once listed on OpenDOAR are now excluded, four are listed in ROAR and one is listed in DATAD-R. Searches on the institutions' websites and IRs revealed that five repositories are inaccessible and only two are searchable. Three institutions blocked access completely, while two institutions were unsearchable. Two universities registered their OA/IR policies with the Registry of Open Access Repositories Mandates and Policies (ROARMap) in 2014, but as of 2019, they had been delisted.

Table 1 Institutional repositories of Zimbabwe's public universities

\begin{tabular}{|c|c|c|c|c|c|c|c|}
\hline University & $\begin{array}{c}\text { Date } \\
\text { established }\end{array}$ & $\begin{array}{l}\text { Registry } \\
\text { listing }\end{array}$ & $\begin{array}{l}\text { No. of } \\
\text { records }\end{array}$ & No. of ETDs & Content format & Software & $\begin{array}{c}\text { Internet } \\
\text { availability }\end{array}$ \\
\hline 1 & 2010 & ROAR & 2162 & 1667 & $\begin{array}{l}\text { Full text (Masters) } \\
\text { Abstract (undergrad) }\end{array}$ & DSpace & Searchable \\
\hline 2 & 2011 & & 64 & 25 & Abstract & DSpace & Searchable \\
\hline 3 & 2012 & & - & 134 & Full text & DSpace & Blocked \\
\hline 4 & 2011 & ROAR & 1,503 & Unknown & No ETDs (IP issues) & DSpace & Unsearchable \\
\hline 5 & 2012 & & 374 & 304 & Abstract & DSpace & Searchable \\
\hline 6 & 2009 & & 401 & - & unknown & DSpace & Blocked \\
\hline \multirow[t]{2}{*}{7} & 2007 & & 121 & - & Abstract & Greenstone & Unsearchable \\
\hline & 2010 & ROAR & 450 & & No ETDs & DSpace & Searchable \\
\hline 8 & 2012 & $\begin{array}{l}\text { ROAR, } \\
\text { DATAD-R }\end{array}$ & 175 & 62 & unknown & DSpace & Blocked \\
\hline
\end{tabular}

\subsection{Software adopted for repositories}

Data gathered from interviews and $\mathrm{OA}$ and/or IR policies revealed that seven universities use DSpace open-source software, and one uses Greenstone for its ETD project. Four library directors mentioned that they had started their repository programmes with the Greenstone software and two of them discarded it along the way because of difficulties they encountered in using it. One interviewee said:

Staff had challenges, then in terms of speed and ease of use we had reservations again. So, we decided to move to Dspace ... [because it] seems to be more popular than Greenstone ... When we face problems it's easier to get assistance from others.

Two universities continue to use Greenstone for their examinations and undergraduate dissertations repositories.

\subsection{Challenges faced in developing ETD repositories}

Four universities took six months to one year to implement functional repositories. One of the institutions did not face any difficulties because senior management were aware of the importance of IRs, but three universities faced stakeholder resistance leading to delays in starting their IR project. One of the interviewees said:

People were not interested; they thought that we were creating an opportunity for those people who want to plagiarise, if works were to be exposed on the internet ... So, we had to continue working on those perceptions.

The universities had a challenge finding skilled IT personnel to deal with the technical challenges experienced with the Greenstone software. Even though University 1 was an early adopter of the idea of ETD repositories, the technical challenges and lack of staff skilled in IT made implementation very slow. In addition, institutions could not recruit additional staff to maintain the repositories due to a job freeze imposed by the government. While the universities' research policies mandate the deposit of TDs, only two institutions specifically mandate the deposit of ETDs. Clause 5.1 of University 3's IR policy stipulates that TDs must be submitted to the library within fourteen days of publication of the official dissertation examination result. Respondents indicated that their institutions do not require students to submit electronic copies of TDs and, to obtain printed copies, they repeatedly have to implore departments to submit TDs to the library. 


\section{Discussion}

The UTAUT social influence variable affected universities' decisions to use internal repositories for on-campus consumption of ETDs, as the universities were concerned about the quality of ETDS that might be accessible in an OA repository. This finding confirms UNESCO's (2001) assertion that TDs expose the quality of intellectual output of a university's graduates and its ability to guide and support original research by students. The finding, that most of the universities mandate deposit of paper copies of TDs and do not specifically require deposit of ETDs, is detrimental to acceptance and adoption of the ETD concept by academics and students. Some of the universities have ETDs while others do not. Facilitating conditions for the adoption of ETDs are largely absent and the universities' policies are not in step with one another. This result resonates with findings of Yiotis (2008) in that a 'mixed bag' of policies existed in universities. Continual inaccessibility to most of the repositories defeats the objective of making students' work visible to a wide audience internationally and limits the exposure of the institution and its scholars (their research interests or areas of expertise) and limits possibilities of collaborative research initiatives. Such conditions do not facilitate sharing and dissemination of student research to a global audience. The OpenDOAR has excluded the universities' repositories because the registry only collects and provides information for sites that permit access to full-text resources by academic researchers. Sites that restrict access in any form or provide metadata only are excluded, as are sites that are continuously inaccessible (OpenDOAR n.d). It is evident from the results of this study that the development of ETD projects in the public academic libraries is quite slow. However, this state of development of ETD projects is not unique to Zimbabwe. A study by Ezema and Ugwu (2013) found that, despite universities in Nigeria having large collections of TDs, only three institutions were running ETD projects.

Seven universities use the DSpace open-source software to host their ETD projects due to the popularity of this software by universities in the country, thus rendering it easy to use. The decision to adopt the software by the majority of the libraries was influenced by the 'effort expectancy' variable of the UTAUT. Studies (Masrek \& Hakimjavadi 2012, Rieh et al. 2007, Witten et al. 2005, Xia \& Opperman 2010) have found that the DSpace platform is preferred by many universities due to its flexibility for customisation. Among the challenges faced by libraries in developing ETD projects and IRs is concern among some in the scholarly community about making grey literature freely available on the web. This concern indicates that sensitisation of stakeholders to the benefits of depositing grey literature like ETDs into repositories needs to be addressed by the libraries to allay scholars' fears. A study by Ramirez et al. (2013) revealed that journal editors and university presses do not regard ETDs as prior publications, therefore manuscripts drawn from these can be submitted for possible publication. The authors recommend that scholars and students be made aware of this view. However, Ramirez et al. (2013) also found that smaller presses were not willing to publish works derived from ETDs, as they considered them a threat to their business. Thus, the 'performance expectancy' variable influences acceptance and usage of the ETD and IR innovations in public academic institutions.

It would not be fair to ignore the economic environment in which universities in Zimbabwe were operating from the start of the repository initiative. The environment is characterised by inflation and is economically constrained. "Setting up a repository is a major undertaking for an institution" (Cullen \& Chawner 2011: 462), requiring financial and human resources for establishing and maintaining it. Careful thought had to be put into the issue before Zimbabwean universities committed to an IR project which they would not be able to sustain in the long run. The constrained financial situation of the universities explains the job freeze which crippled efforts to recruit additional skilled staff specifically for the management and maintenance of repositories.

\section{Conclusion and recommendations}

It is evident that development of ETD programmes in Zimbabwe's public universities is very slow amid challenges of stakeholder buy-in to IRs and ETD initiatives and the lack of management support for successful implementation. The following recommendations are made:

- The institutions in this study should mandate deposit of electronic copies of TDs to populate their repositories so that they increase findability of student research output.

- The universities should endeavour to provide full-text ETDs so that they contribute meaningfully to scholarly debate and knowledge sharing.

- Promotion of awareness of the repositories and benefits accruing to stakeholders needs to be expedited through workshops so that concerns and fears of researchers and students are alleviated for the good of the institution, its research community and the country at large. 


\section{References}

Abrahams, L., Burke, M., Gray, E. and Rens, A. 2008. Opening access to knowledge in Southern African universities. Cape Town: Southern African Regional Universities Association (SARUA).

Abrahams, L., Burke, M. and Mouton, J. 2010. Research productivity-visibility-accessibility and scholarly communication in Southern African universities. The African Journal of Information and Communication, (10): 20-36. DOI:10520/EJC-15eeffcbb5.

Adams, J., King, C. and Hooks, D. 2010. Global research report: Africa. Leeds: Thomson Reuters.

Association of African Universities (AAU). 2019. Database of African theses and dissertations - research (DATAD-R). [Online]. https://www.aau.org/current-projects/database-of-african-theses-and-dissertations-research-datad-r/. (19 August 2019).

Bankier, J.G. and Perciali, I. 2008. The institutional repository rediscovered: what can a university do for open access publishing? Serials Review, 34(1): 21-26. DOI:10.1080/00987913.2008.10765147.

Boock, M. and Kunda, S. 2009. Electronic theses and dissertation metadata workflow at Oregon State University libraries. Cataloging and Classification Quarterly, 47(3-4): 297-308.

Chudnov, D. 2001. DSpace: durable digital documents. Serials, 14(3): 284-285. [Online]. https://dspace.mit.edu/bitstream/handle/1721.1/26702/Chudov_2001_DSpace.pdf?sequence=1\&isAllowed=y (22 September 2019).

Cullen, R. and Chawner, B. 2011. Institutional repositories, open access, and scholarly communication: a study of conflicting paradigms. The Journal of Academic Librarianship, 37(6):460-470. DOI:10.1016/j.acalib.2011.07.002.

Early, M.G. and Taber, A.M. 2010. Evolving in collaboration: electronic thesis and dissertation workflows in North Carolina. Collaborative Librarianship, 2(1). [Online]. https://digitalcommons.du.edu/collaborativelibrarianship/vol2/iss1/3 (16 August 2021).

Ezema, I.J. and Ugwu, C.I. 2013. Electronic theses and dissertations in Nigeria university libraries: Status, challenges and strategies. The Electronic Library, 31(4): 493-507. DOI: 10.1108/EL-08-2011-0118.

Fox, E.A. 2001. Overview of a guide for electronic theses and dissertations. [Online]. https://eprints.cs.vt.edu/archive/00000624/01/OASndltd14refs.pdf_(12 September 2019).

Fox, E.A., MacMillan, G. and Srinivasan, V. 2012. Electronic theses and dissertations, progress, issues and prospects, In T.W. Luke and J. Hunsinger. Eds. Putting knowledge to work and letting information play. Blacksburg: Virginia Tech. 95-110.

Harnad, S. 2011. Open access to research: changing researcher behavior through university and funder mandates.. JeDEM 3(1): 33-41. DOI:10.29379/jedem.v3i1.54.

Kotecha, P., Walwyn, D. and Pinto, C. 2011. Deepening research capacity and collaboration across universities in SADC: a southern African regional universities research and development fund. Johannesburg: Southern African Regional Universities Association.

Lynch, C.A. 2003. Institutional repositories: essential infrastructure for scholarship in the digital age. portal: libraries and the academy, 3(2): 327-336. [Online]. http://muse.jhu.edu/journals/pla/summary.v003/3.2lynch.html. (23 July 2015).

Lynch, C. 2017. Updating the agenda for academic libraries and scholarly communications. College and Research Libraries, 78(2): 126-130. DOI:10.5860/crl.78.2.126.

Masrek, M.N. and Hakimjavadi, H. 2012. Evaluation of three open source software in terms of managing repositories of electronic theses and dissertations: a comparison study. Journal of Basic Applied Science Research, 2(11):1084310852.

McCutcheon, S. 2011. Basic, fuller, fullest: treatment options for electronic theses and dissertations. Library Collections, Acquisitions and Technical Services, 35(2-3): 64-68. DOI:10.1080/14649055.2011.10766300.

Mouton J., Boshoff, N., de Waal, L., Esau, S., Imbayarwo, B., Ritter, M. \& van Niekerk, D. 2008. The state of public science in the SADC region. Stellenbosch: SARUA.

Moxley, J.M. 2001. Universities should require electronic theses and dissertations. Educause Quarterly, 3: 61-3. [Online]. www.educause.edu/ir/library/pdf/EQM0139.pdf (18 September 2019).

Nordling, L. 2018. What is Africa's real share of global science? [Online]. http://www0.sun.ac.za/scistip/news/what-doesafrica-contribute/ (16 September 2019).

OpenDOAR. n.d. About OpenDOAR. [Online]. http://v2.sherpa.ac.uk/opendoar/information.html (20 September 2019).

Oye, N., lahad, N.A. and Rahim, N.A. 2012. Behavioural intention to accept and use ICT in public university: integrating quantitative and qualitative data. Journal of Emerging Trends in Computing and Information Science, 3(6).

Perrin, J.M., Winkler, H.M. and Yang, L. 2015. Digital preservation challenges with an ETD collection - a case study at Texas Tech University. Journal of Academic Librarianship, 42: 98-104. DOI:10.1016/j.acalib.2014.11.002.

Prost, H. and Schopfel, J. 2014 Degrees of openness: access restrictions in institutional repositories. D-Lib Magazine, 20(7/8). DOI:10.1045/july2014-prost.

Ramirez, M.L., Dalton, J.T., McMillan, G., Read, M. and Seamans, N.H. 2013. Do open access electronic theses and dissertations diminish publishing opportunities in the social sciences and humanities? Findings from a 2011 survey of academic publishers. College \& Research Libraries, 74(4): 368-380. DOI:10.5860/crl-356.

Ravikumar, M.N. and Ramanan, T. 2014. Comparison of Greenstone digital library and DSpace: experiences from digital library initiatives at Eastern University, Sri Lanka. Journal of the University Librarians Association of Sri Lanka, 18(2): 76-90. 
Rieh, S.Y., Markey, K.K., St. Jean, B., Yakel, E. and Jihyun, K. 2007. Census of institutional repositories in the U.S.: a comparison across institutions at different stages of IR development. D-Lib Magazine, 13(11/12). [Online]. http://www.dlib.org/dlib/november07/rieh/11 rieh.html (8 June 2015).

Schöpfel, J. 2010. Towards a Prague definition of grey literature. Paper presented at the $12^{\text {th }}$ International Conference on Grey Literature (GL12), 6-7 December, Prague.

Schöpfel, J. and Rasuli, B. 2018. Are electronic theses and dissertations (still) grey literature in the digital age? A FAIR debate. The Electronic Library, 36(2): 208-219. DOI:10.1108/EL-02-2017-0039.

Suleman, H. and Fox, E.A. 2003. Leveraging OAl harvesting to disseminate theses. Library Hi Tech, 21(2): $119-227$. DOI:10.1108/07378830310479857.

Swan, A. 2009. Open access institutional repositories: a briefing paper. [Online]. http://www.thailibrary.in.th/wpcontent/uploads/2013/02/open_access_institutional_repositories.pdf (20 August 2021).

Trotter, H., Kell, C., Willmers, M., Gray, E. and King, T. 2014. Seeking impact and visibility: scholarly communication in Southern Africa. Cape Town: African Minds 357. [Online].

http://open.uct.ac.za/bitstream/handle/11427/2310/SCAP_Trotter_SynthesisReport_2014.pdf?sequence=1 (20 February 2015).

United Nations Educational, Scientific and Cultural Organization (UNESCO). 2001. The guide for electronic theses and dissertations. [Online]. http://dl.cs.uct.ac.za/sites/default/files/etdguide.pdf (16 September 2019).

Venkatesh, V., Morris, M.G., Davis, G.B. and Davis, F.D. 2003. User acceptance of information technology: toward a unified view. MIS Quarterly 27(3): 425-478. DOI:10.2307/30036540.

Witten, I.H., Bainbridge, D., Tansley, R., Huang, Chi-Yu and Don, C.J. 2005. StoneD: a bridge between Greenstone and DSpace. D-Lib Magazine, 11(9). [Online]. http://www.dlib.org/dlib/september05/witten/09witten.html (13 September 2016).

World Bank and Elsevier. 2014. A decade of development in Sub-Saharan African science, technology, engineering and mathematics research. [Online]. http://wwwwds.worldbank.org/external/default/WDSContentServer/WDSP/IB/2014/09/26/000456286_20140926094154/Render ed/PDF/910160WP0P126900disclose09026020140.pdf (17 February 2015).

Xia, J. and Opperman, D.B. 2010. Current trends in institutional repositories for institutions offering Master's and Baccalaureate Degrees. Serials Review, 36:10-18.

Yiotis, K. 2008. Electronic theses and dissertations (ETD) repositories. What are they? Where do they come from? How do they work? OCLC Systems \& Services: International digital library perspectives, 24(2): 101-115.

DOI:10.1108/10650750810875458. 